\title{
Saúde mental, intersetorialidade e questão social: um estudo na ótica dos sujeitos
}

\author{
Mental health, intersectors and social issue: \\ a study from the subjects' point of view
}

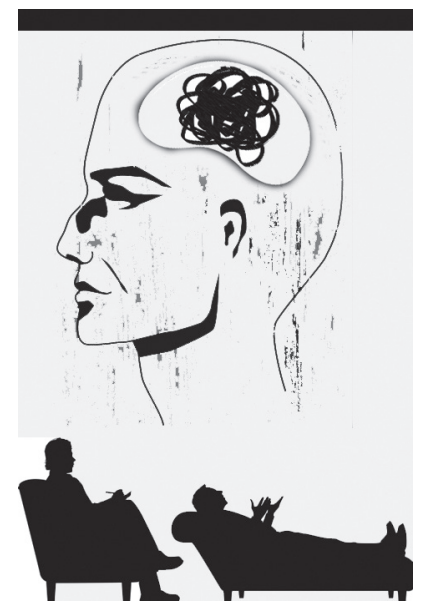

\section{Graziela Scheffer* Lahana Gomes Silva**}

Resumo: O estudo ora apresentado é resultado de uma pesquisa qualitativa com os profissionais e usuários do Centro de Atenção Psicossocial (CAPS) que visou identificar o acesso dos portadores de transtorno mental na rede "atenção em saúde mental" e do trabalho intersetorial da equipe. A investigação é fruto do trabalho de conclusão de curso de Serviço Social vinculado ao Grupo de Estudos e Extensão — "Saúde, Interdisciplinaridade e Cidadania". Os resultados obtidos nos ofereceram um panorama dos desafios e avanços da Reforma Psiquiátrica no cotidiano do trabalho profissional e da vida social dos portadores de transtorno mental.

Palavras-chave: Saúde mental. Reforma psiquiátrica. Rede de atenção. Serviço Social.

\begin{abstract}
This article resulted from a qualitative research with both professionals and users of the Psychosocial Care Center, and it aimed at identifying the access of patients with mental disorders to the group "care in mental health", as well as the team's intersectional work. The research was done as part of the completion of Social Service course paper, and it was linked to the Group of Study and Extension called Health, Interdisciplinarity and Citizenship. The results give us a view of the challenges and advances of the Psychiatric Reform both in the daily professional work and in the social life of patients with mental disorders.
\end{abstract}

Keywords: Mental health. Psychiatric reform. Group of care. Social Service.

* Assistente social, doutoranda em Serviço Social (UFRJ) Rio de Janeiro/RJ, Brasil; mestre em Serviço Social (UFRJ), especialista em Saúde Mental Coletiva (ESP-RS), professora da Universidade Federal do Tocantins (UFT), coordenadora do Grupo de Estudos e Extensão — Saúde, Interdisciplinaridade \& Cidadania (GESIC). Departamento de Fundamentos Históricos Teóricos e Metodológicos. Email: grazi.email@ibest.com.br.

** Estudante de Serviço Social da Universidade Federal do Tocantins (UFT), integrante do Grupo de Estudos e Extensão — Saúde, Interdisciplinaridade \& Cidadania (Gesic). 


\section{Introdução}

Reforma Psiquiátrica está alicerçada, no Sistema Único de Saúde
(SUS), seus princípios norteadores: saúde, como um direito fun-
damental e dever do Estado, enfatizando o acesso universal na
atenção em saúde mental com base em integralidade, intersetorialidade, equidade, universalidade, igualdade e no controle social. Os CAPS têm como função promover a inserção social das pessoas com transtornos mentais, por meio de ações intersetoriais e regular a porta de entrada da rede de assistência em saúde mental na sua área de atuação, dando suporte à atenção em saúde mental na rede básica. O processo de trabalho em saúde mental está pautado em uma concepção ampliada de saúde com base no SUS, implicada numa relação com o contexto econômico, social e cultural do país; ou seja, abrangem situações de moradia, saneamento, renda, alimentação, educação, acesso ao lazer e bens. Essa nova concepção busca abrir canais de democratização dos saberes profissionais, bem como das informações acerca do processo de saúde/sofrimento psíquico (Machado, 2009). Justificamos a importância do estudo a partir de nossas observações no trabalho no CAPS, onde tem havido dificuldades na inserção social e na saída — alta — dos usuários. Nesse sentido, precisamos investigar a temática da saúde mental a fim de criar propostas cotidianas efetivas em consonância com a Reforma Psiquiátrica e o Projeto Ético-político profissional.

\section{Da reforma psiquiátrica ao trabalho do assistente social}

Em 1960, o Brasil estava em plena crise e luta na saúde mental, devido ao fechamento dos leitos públicos e o apoio às clínicas particulares, desencadeando, assim, uma onda privatista chamada pelos estudiosos do período de "indústria da loucura. ${ }^{1}$ A mercantilização do serviço de Saúde Mental promovida pelo

1. Com o golpe de 1964 aprofundaram-se a lógica autoritária, privatizante e mercantilista na terceirização da assistência psiquiátrica; assim, na ditadura, os militares tinham total permissão para internar pessoas, sendo uma forma de calar a boca dos indivíduos. 
setor financeiro e as grandes corporações médicas fizeram da doença mental um objeto precioso de lucro. Essa violenta privatização na saúde gerou "rebeldias e resistência" de dois movimentos organizados que surgiram concomitantemente no final dos anos 1970: o movimento de Reforma Sanitária e o Movimento de Reforma Antimanicomial (Amarante, 1994; Amarante, 2007; Costa, 1989). Na década de 1970, em plena Ditadura Militar, surgem os movimentos dos trabalhadores, usuários e familiares pela a mobilização da luta antimanicomial e de reforma sanitária. Ao observar um balanço do período dessa longa e lenta experimentação da Reforma Psiquiátrica no Brasil, na década de 1970, no contexto político de luta pelos direitos da saúde nova rumos foram tomados na saúde pública brasileira.

Pode-se dizer que o processo da Reforma Psiquiátrica Brasileira é contemporâneo ao movimento sanitário, nos anos de 1970. Entretanto, é a Reforma Sanitária que dá sustentação política à Reforma Psiquiátrica, até que ela se firme como um movimento social independente. (Silveira, 2009, p. 37)

Foi na década de 1970, para adequar solução de problemas específicos do Estado do Bem-Estar Social e o processo do capitalismo no progresso econômico junto ao comando psiquiátrico, que surge a doutrina que embasa o processo da psiquiatria no Brasil no final da década de 1970. No contexto político de movimento e luta pela democracia em 1979, os trabalhadores em saúde mental se reuniram para realizar seu primeiro movimento em favor de uma nova psiquiatria, uma manifestação popular, a primeira luta antimanicomial realizada em São Paulo/SP (Amarante, 1994).

Ao entrar em cena, o movimento de trabalhadores de saúde mental organizou suas ideias e propôs objetivos relacionados à melhoria da rede ambulatorial e de saúde mental, tais como: extinção dos leitos em hospitais psiquiátricos; regionalização do atendimento e nas ações em saúde mental; controle das internações na rede dos hospitais e nos serviços privados e públicos; expansão de rede ambulatorial em saúde com equipes multiprofissionais de saúde mental. Nesse último objetivo, a proposta indicou a necessidade da atuação de profissionais como Psiquiatras, Psicólogos e Assistentes Sociais; se necessário também Enfermeiros, Terapeutas Ocupacionais e Fonoaudiólogos. O último objetivo proposto foi a humanização social dentro dos asilos públicos e privados, com 
uma equipe multiprofissional nos mesmos moldes já citados no objetivo anterior (Vasconcelos, 2000).

No processo de democratização nos anos 1980, houve também as ações integradas de saúde. Tal ação estava ligada à expansão do modelo sanitarista e o Sistema Único de Saúde, que deu ênfase somente aos princípios em lei para o SUS a partir dos anos 1990 (Amarante, 2007). Também nesse período, a Previdência Social chega à crise financeira, e assim, o próprio Estado chega a tomar as medidas possíveis para restabelecer a psiquiatria em um instrumento de cura sem violência e ganância (Amarante, 1994). A mobilização teve um objetivo de denúncias, reivindicações e aprovação da Lei n. 180, que teve o surgimento a partir da reforma psiquiátrica italiana estabelecida no fechamento da porta de entrada dos hospitais psiquiátricos na Itália. As denúncias eram pela humanização dos hospitais psiquiátricos, privados e públicos (Amarante, 2002).

Os objetivos não foram atendidos de imediato. Através dos movimentos juntos, podemos dizer "juntos e misturados", o poder e a força cresceram e levantaram a bandeira "para uma sociedade sem manicômios". Luta esta que desempenhava a implantação de serviços substitutivos aos hospitais psiquiátricos (Vasconcelos, 2000).

Vasconcelos (2000) aponta que a Saúde Mental entrou numa nova conjuntura, em níveis municipais, estaduais e federais no Brasil, mobilizada pela I Conferência Nacional de Saúde em 1986; também neste mesmo ano criou-se o primeiro Centro de Atenção Psicossocial (CAPS) no Brasil, como aponta Ministério da Saúde e a Secretaria de Atenção à Saúde Mental:

O primeiro Centro de Atenção Psicossocial (CAPS) do Brasil foi inaugurado em março de 1986, na cidade de São Paulo: Centro de Atenção Psicossocial Professor Luiz da Rocha Cerqueira, conhecido como CAPS da Rua Itapeva. A criação desse CAPS e de tantos outros, com outros nomes e lugares, fez parte de um intenso movimento social, inicialmente de trabalhadores de saúde mental, que buscavam a melhoria da assistência no Brasil e denunciavam a situação precária dos hospitais psiquiátricos, que ainda eram o único recurso destinado aos usuários portadores de transtornos mentais. (Brasil, 2001, p. 12)

Nesse contexto apontado pelo Ministério da Saúde, é importante ressaltar que os Centros de Atenção Psicossocial (CAPS) foram criados para ser um 
substitutivo às internações em hospitais psiquiátricos, onde o tratamento da "loucura" era realizado com acompanhamento clínico e a reinserção social dos usuários pelo acesso ao lazer, trabalho, exercício dos direitos civis e fortalecimento dos laços familiares e comunitários (Amarante, 2007).

Diante disso, houve a I Conferência Nacional de Saúde Mental em 1987 que teve como proposta exigir a Reforma Psiquiátrica, motivada pelas denúncias de maus-tratos e violência nos pacientes. Mas o maior avanço dos anos 1980 foi a aprovação da Constituição Federal de 1988. Com a Constituição, houve a criação do Sistema Único de Saúde (SUS), reconhecendo o direito à saúde para todos, colocando o Estado como responsável em garantir os direitos sendo ele o comandante único para a promoção de saúde (Mattos, 2001).

\begin{abstract}
A partir de 1988, com a criação do Sistema Único de Saúde (SUS), que tem como princípios norteadores a saúde como direito fundamental e o dever do Estado de garanti-la, também enfatiza a integralidade, a equidade, a universalidade e a participação da população usuária, de modo que a visão de atenção em saúde busca ações para além dos fatores biológicos, pois ela é compreendida numa relação com o contexto econômico, social e cultural do País, ou seja, os processos de saúde/doença abrangem situações de moradia, saneamento, renda, alimentação, educação, lazer e acesso aos bens. (Nunes, Machado e Bellini, 2003, p. 3)
\end{abstract}

Em 19 de setembro de 1990 foi sancionada a Lei n. 8.080, que dispõe sobre as promoções, proteção e recuperação da saúde. A lei consiste no conjunto de órgãos públicos federais, estaduais e municipais ligados em um só sistema, que se referia ao Sistema Único de Saúde (SUS). O SUS tem como seus princípios a universalidade, ou seja, todos no Brasil devem ter acesso aos serviços de saúde, sem se levar em conta sexo, renda, etnia, ocupação, contribuição, ou outras características sociais ou pessoais; a integralidade como o acesso aos trabalhadores da saúde e a prevenção de doenças e epidemias; na descentralização, que estabelece que o Estado e o município tenham um poder indispensável no fortalecimento do acesso no sentido da igualdade (Brasil, 1990). Em 1992, houve, no Brasil, uma grande conquista no avanço da desinstitucionalização psiquiátrica, descentralização das ações de saúde, diretrizes do Sistema Único de Saúde (SUS), universalidade e integralidade. Essas conquistas são materializadas na II Conferência Nacional de Saúde Mental (Amarante, 1995). 
Diante disso, cabe destacar a implantação da rede de atenção psicossocial na substituição dos manicômios para o espaço aberto e a ocorrência de vínculo comunitário:

Os princípios da reforma psiquiátrica remetem à realidade social dos sujeitos em sofrimentos psíquico, pois as condições de vida de muitos desses sujeitos evidenciam todas as contradições que o modelo de reforma introduz, considerando a realidade sócio-histórica desses sujeitos, os quais, embora algumas vezes libertos dos muros e das grades dos manicômios, encontram-se amarrados às estruturas sociais difíceis de serem quebradas. Estruturas estas decorrentes da realidade histórico-social das famílias, da comunidade, dos serviços públicos, da sociedade estabelecido e regente de todas as relações que se estabelecessem entre as pessoas. (Rabelo, Tavares e Faria, 2009, p. 94)

Em 2001 chega ao fim o impasse da aprovação da Lei n. 10.216/2001, sancionada em 6 de abril de 2001. A lei direciona e redireciona a Atenção à Saúde Mental, que regulamenta a não internação dos indivíduos que têm transtorno mental; consiste também em um novo modelo de assistência psiquiátrica na internação social do usuário com transtorno mental, bem como a implantação de Residências Terapêuticas e Centros de Atenção Psicossocial e direitos colocado pelo Estado para os usuários com transtorno mental (CAPS) (Vasconcelos, 2008). A transformação dos Serviços de Saúde Mental rompe com fatores vivenciados pelos usuários, historicamente cruéis e desumanos. A visão do tratamento com os usuários hoje é intenso e aberto, sem precisar de regimento asilar e injusto.

A nova concepção de saúde mental, que visa priorizar o indivíduo e não a doença, oferecendo-lhe tratamento humanizado e de qualidade, resultou na criação de novos mecanismos e espaços de tratamento que provocam para a necessidade de uma ação intersetorial com as demais políticas sociais e de um trabalho pautado no fortalecimento e atuação em rede, que possibilite uma intervenção integrada, visando à integralidade no atendimento ao usuário. (Bredow e Dravanz, 2010, p. 232)

Entretanto, o avanço da Reforma Psiquiátrica, contraditoriamente, ocorreu no período de contrarreforma do Estado brasileiro: 
Paradoxalmente, políticas neoliberais de desinvestimento em políticas sociais públicas em geral, induzem a processo de desospitalização, já que a manutenção das instituiçôes psiquiátricas convencionais constitui item de custo elevado para o Estado. Nessa modalidade, a tendência é gerar processos sem garantia de assistência na comunidade, provocando negligência social e aumento da população de rua, incluindo portadores de transtorno mental. (Vasconcelos, 2000, p. 21)

A intersetorialidade na saúde mental coloca o usuário em uma nova concepção, não como doente, mas como pessoa que necessita ser um indivíduo humanizado e reconhecido dentro da sociedade e, para isso, foi preciso fortalecer as redes e trazer com elas as políticas sociais que intervêm visando a integralidade do usuário (Severo e Dimenstein, 2011).

[...] a intersetorialidade, através da articulação saúde mental-cultura, é muito potente na construção de parcerias com outros grupos sociais na conquista de outro lugar para a loucura no âmbito social. Serviços e políticas públicas norteadas pela atenção psicossocial devem priorizar a intersetorialidade como uma estratégia fundamental na construção de projetos de saúde, de solidariedade e de participação social, tornando os sujeitos ativos na produção de saúde. (Severo e Dimenstein, 2011, p. 650)

Portando, a saúde mental deve ser articulada sempre com a intersetorialidade, pois supera a lógica histórica da fragmentação das políticas públicas no enfrentamento da questão social. Silveira (2009) aponta o CAPS como um importante coordenador da rede e um apoiador da gestão, tendo impasses com outras redes sociais e outros setores vinculados na sociedade.

Os CAPS têm o papel de coordenar a rede de atenção em SM e apoiar a gestão, desenvolvendo atividades básicas, tais como: atendimento psicoterápico, tratamento medicamentoso, atendimento à família, atividades comunitárias, suporte social, desenvolvimento de oficinas culturais, visitas domiciliares e desintoxicação ambulatorial. (Silveira, 2009 p. 47).

Os principais serviços que compõem as redes de atenção à saúde mental são: unidades de saúde, centro de atenção psicossocial, residência terapêutica, 
consultório de rua, ambulatório, pronto-socorro, hospitais gerais e SAMU, sendo que a rede de atenção à saúde mental abrange toda a comunidade. E há, ainda, a porta de entrada da rede, que são os CAPS; eles são os articuladores, reguladores e organizadores da rede que abrange seu território.

Estamos falando do princípio da intersetorialidade, isto é, de estratégias que perpassem vários setores sociais, tanto do campo da saúde mental e saúde em geral, quanto das políticas públicas e da sociedade como um todo. Em outras palavras, os serviços de atenção psicossocial devem sair da sede dos serviços e buscar na sociedade vínculos que complementem e ampliem os recursos existentes. Deve articular-se com todos os recursos existentes no campo da saúde mental, isto é, com Rede de Atenção à Saúde Mental (outros serviços de atenção psicossocial, cooperativas, residências de egressos ou outras pessoas em situação de precariedade social, ambulatórios, hospitais-dia, unidades psiquiátricas em hospitais gerais), e no campo da saúde em geral (Estratégia Saúde da Família, centros de saúde, rede básica, ambulatório, hospitais gerais e especialização etc.) ou no âmbito das políticas públicas em geral (ministério público, previdências sociais, delegacias, instituição para crianças, idosos, desassistidos em geral, igrejas, políticas educacionais, de esporte, lazer, cultura e arte, turismo, transporte, ação e bem-estar social etc.), e, finalmente, no âmbito dos recursos criados pela sociedade civil para organizar-se, defender-se, solidarizar-se. (Amarante, 2007, p. 86)

A Portaria n. 3.088, de 23 de dezembro de 2011, refere-se ao funcionamento da rede de atenção da saúde mental e contém as seguintes diretrizes:

I — Respeito aos direitos humanos, garantindo a autonomia e a liberdade das pessoas;

II — Promoção da equidade, reconhecendo os determinantes sociais da saúde;

III - Combate a estigmas e preconceitos;

IV — Garantia do acesso e da qualidade dos serviços, ofertando cuidado integral e assistência multiprofissional, sob a lógica interdisciplinar;

$\mathrm{V}$ - Atenção humanizada e centrada nas necessidades das pessoas;

VI - Diversificação das estratégias de cuidado;

VII - Desenvolvimento de atividades no território, que favoreçam a inclusão social com vistas à promoção de autonomia e ao exercício da cidadania; 
VIII — Desenvolvimento de estratégias de Redução de Danos;

IX - Ênfase em serviços de base territorial e comunitária, com participação e controle social dos usuários e de seus familiares;

$\mathrm{X}$ - Organização dos serviços em rede de atenção à saúde regionalizada, com estabelecimento de ações intersetoriais para garantir a integralidade do cuidado; XI — Promoção de estratégias de educação permanente; e

XII - Desenvolvimento da lógica do cuidado para pessoas com transtornos mentais e com necessidades decorrentes do uso de álcool, crack e outras drogas, tendo como eixo central a construção do projeto terapêutico singular. (Brasil, 2011, p. 3)

A importância do Serviço Social na Saúde Mental cresceu, ainda mais, com a inclusão dos usuários e familiares nas políticas, ações de cidadania e ações de direitos do sujeito e na questão social que vivencia o usuário e sua família. Hoje essa realidade mudou para melhor atender o sujeito com transtorno mental enquanto sujeito portador de direitos. O Serviço Social tem um papel diferenciado para complementar a equipe multidisciplinar nos CAPS, que promove na rede uma articulação de direitos sociais:

[...] que o destaque conferido aos direitos sociais está ligado à construção do "novo" habitus (produto do Projeto Ético-Político da Profissão) que impulsiona um "novo" capital simbólico, que é fortalecido pela orientação da Reforma Psiquiátrica e pelas conquistas democráticas presentes na Constituição (1988, que garante na forma legal os direitos sociais e que permitem à profissão acioná-los no enfrentamento da questão social). (Machado, 2009, p. 105)

A Reforma Psiquiátrica rompe o modelo biomédico e psicologizante da questão social para um modelo psicossocial pautado no reconhecimento da cidadania e da subjetividade na produção da loucura.

O Serviço Social trabalha nas múltiplas expressões da questão social nas esferas privadas e nas públicas com as gestões de políticas sociais, planejamentos, formulação e avaliação de programas e projetos.

[...] profissional de serviço social é formado para trabalhar em diversos tipos de ações, em empresas, em comunidades, em saúde, em serviços de infância e 
na Justiça, entre outros. Seu leque de opções no mercado de trabalho é variado, embora seja insuficiente o número de profissionais contratados. Sua capacitação, que o habilita a estar à frente das mais diversas realidades, ajuda-o a trabalhar com a saúde mental, que envolve de tudo um pouco. Vale lembrar que a questão social está presente em todos os lugares e expressa-se nas mais diversas formas, trazendo impasses para as equipes multidisciplinares. Para o enfrentamento dessa realidade, portanto, faz-se necessário o trabalho do assistente social, que ocupa assim um lugar estratégico e diferenciado nessas equipes. (Leme, 2013, p. 14)

Podemos então dizer que a intervenção profissional no campo da saúde mental na interface com a questão social está interconectada com envolvimento do usuário nos seus direitos como cidadão:

O fazer do assistente social está localizado na trama das relações loucura/exclusão/ discriminação e política de saúde mental/políticas públicas, que vão se delineando e se particularizando no cotidiano na questão social. (Machado, 2009, p. 83)

Entretanto, não cabe só ao assistente social como a toda equipe se envolver nas articulações das redes em saúde mental promovendo, assim, o fortalecimento da cidadania e inserção social do usuário da saúde mental. Atualmente, o trabalho em saúde mental mudou, exigindo cada vez mais ações intersetoriais e interdisciplinares, a fim de garantir a integralidade do atendimento. O processo trabalho envolve

As reuniões com equipes e usuários da instituição, bem como assembleias de usuários, as pesquisas qualitativas do tipo etnográfico-etnológico, os processos avaliativos com a participação dos atores sociais, tipo pesquisa-ação, pesquisa social de avaliação/intervenção, as metodologias de grupo focal e grupo de discussão, e os projetos de construção de metodologias integradas com abordagem multifacetada, complexa, são exemplos de orientação e tendência que o campo da avaliação vem demonstrando progressivamente no bojo das transformações maiores das políticas públicas de saúde mental em contexto de Reforma Psiquiátrica atualmente. (Pinheiro, Guljor, Junior e Mattos, 2007, p. 59) 
A intervenção do Assistente Social nos CAPS é o trabalho que se defronta com novas demandas compartilhadas com a equipe, que torna o processo de trabalho em saúde mental cada vez mais "coletivo" e "democrático" (Machado, 2009, p. 103). Em síntese do exposto, consideramos que avançamos a partir da Reforma Psiquiátrica; entretanto, precisamos ainda mais nesse cenário de precarização do trabalho e das políticas públicas, como poderemos verificar na exposição do item seguinte.

\section{A arte do encontro: uma análise do acesso à rede de saúde mental}

"A vida é a arte do encontro, embora haja tanto desencontro pela vida"

(Vinicius de Moraes)

O objetivo da pesquisa foi identificar o trabalho intersetorial e o acesso à rede de atenção à saúde mental na perspectiva dos profissionais da equipe e dos usuários inseridos no CAPS em Palmas/TO. Portanto, o estudo enfatizou a análise sobre trabalho intersetorial no acesso à rede na visão dos profissionais e dos usuários. Os dados foram coletados por meio de entrevistas semiestruturadas no primeiro semestre de 2012. A análise sintetiza os dois ângulos investigativos: os sujeitos que trabalham (profissionais) e os sujeitos que "utilizam" o CAPS e as redes. ${ }^{2}$ Portanto, o resultado representa um encontro desses sujeitos interpretado à luz da reflexão das pesquisadoras. O resultado é apresentado conforme abaixo em eixos temáticos.

\subsection{0 s sujeitos entrevistados}

Com relação à identificação do sujeito-usuário que foi solicitado nas entrevistas: idade, sexo, raça/cor, se trabalhavam, sua renda familiar mensal

2. O estudo foi autorizado pelo Comitê de Ensino, Trabalho e Pesquisa da Secretaria Municipal de Saúde de Palmas do Tocantins, em 16 de dezembro de 2011. Os participantes foram oito usuários e cinco profissionais de nível superior. Foi feita a leitura e fornecido do Termo de Consentimento Livre e Esclarecido conforme observância dos procedimentos éticos em pesquisa com pessoas. 
e sua escolaridade, a fim de construirmos um perfil social. Todos entrevistados são mulheres, duas na faixa etária de 40 anos (5 entrevistadas), sendo duas acima de 50 anos e somente uma abaixo dos 30 anos. Em relação à cor e etnia, quatro (4) declararam serem negras, três (3) brancas e uma (1) amarela. Todas as usuárias pesquisadas declararam não trabalhar. A renda familiar de seis (6) entrevistadas é de até um salário mínimo e duas (2) declaram que é de 2 a 3 salários mínimos, sendo que, das usuárias pesquisadas, duas (2) recebem o Benefício de Prestação Continuada (BPC) e uma (1) do Programa Bolsa Família. Todas declararam morar com os familiares e cinco (5) delas declararam ter filhos.

Sobre o grau de escolaridade somente uma (1) usuária declarou ser analfabeta, duas (2) declararam ter cursado até a $5^{a}$ série do Ensino Fundamental, três (3) cursaram Ensino Fundamental Completo e duas (2) declararam ter o Ensino Médio Completo.

Com base nos dados coletados dos perfis das usuárias entrevistadas podemos verificar que elas apresentam condições sociais, econômicas e culturais precárias. Fato esse que as coloca na circunstância com que o Serviço Social e a equipe trabalham que é a certeza de um futuro cheio de miséria, fome, sacrifício e falta de saúde (Vasconcelos, 1997).

Os usuários dos serviços de atenção à saúde mental apresentam formas de vulnerabilidade que têm implicações no acesso a outras políticas sociais, que são: A primeira é "material", pois a maioria dos usuários dos serviços públicos de saúde mental historicamente foi e continua a ser composta de sujeitos em situação de pobreza e miséria, com rupturas no mercado de trabalho. A segunda é "cultural": o "louco" é (ainda) reconhecido como sujeito "estigmatizado". Ainda é visto como "um outro ameaçador" que comete atos violentos, sua fala é "incoerente", "alienada", sendo muitas vezes considerado perigoso para a sociedade. (Machado, 2009, p. 81)

Podemos então destacar que a condição de mulher, negra e pobre além de "louca" agrega um conjunto de estereótipos estigmatizastes na sociedade brasileira que geram preconceitos e discriminações, atrelado a um sistema de opressão e exploração que se converte em dificuldade no acesso à rede e no exercício da cidadania. 
Faleiros (2008, p. 44), enfatiza que o Serviço Social tem o seu objeto de intervenção na relação do usuário/sujeito e seu enfrentamento e luta pela estrutura econômica, social, etnias, gênero e do poder e, ainda, sobre a relação de usuário com a instituição que "emerge o processo de fortalecimento do usuário diante da fragilização de seus vínculos, capitais ou patrimônios individuais e coletivos". Contudo, é notório que não só os assistentes sociais como equipe devem se apreender das particularidades que envolvem as trajetórias dos sujeitos e façam ações de enfrentamento e fortalecimentos dos usuários, contribuindo para exercício cidadania.

Em relação aos profissionais entrevistados foram: (1) Enfermeira, (1) Assistente Social, (2) Psicólogo e (1) Gestora. As profissionais têm de um a três anos completos que trabalham no CAPS II de Palmas, "Casa Feliz". Vale ressaltar que uma das profissionais já trabalhou em outra instituição que abrange a rede de saúde mental do Estado.

\subsection{CAPS e concepção da rede de saúde mental}

Iniciamos o eixo com os profissionais sobre a concepção do papel do CAPS enquanto regulador da porta de entrada da rede assistencial no âmbito do seu território e/ou do módulo assistencial. Duas profissionais não responderam. Uma profissional apresentou que os CAPS têm esse papel, mas não foi clara na sua definição. A outra profissional respondeu que o CAPS não é a porta de entrada na rede, mais sim a atenção básica. Os profissionais desconhecem que o CAPS tem o papel de regulador da porta de entrada.

Foi questionado aos profissionais sobre a política de saúde mental, proposta para CAPS II; todos os (5) os cincos profissionais pesquisados concordaram, deixando claro que esta política é regulamentada pelo Ministério da Saúde com a perspectiva de inclusão e recuperação do usuário.

Em relação ao conhecimento da rede, os profissionais por meio das entrevistadas 1 e 2 não têm conhecimento claro. A profissional 1 entende que "é apenas com o contato da psiquiatria na fonte de recurso da rede pública e privada e o contato com o ambulatório". 
A profissional 2 entende que: “A rede de cuidado à saúde mental é uma substituição aos hospitais psiquiátricos, com o objetivo de inserir o usuário socialmente no mercado de trabalho e assim melhorar sua qualidade de vida". (Entrevistada 2, 2012). As Profissionais 3 e 4 entendem a rede em um quadro mais elevado; a rede de atenção à saúde mental é um serviço que interliga todos os meios sociais, culturais e mais ainda os profissionais da rede básica de saúde, Estratégia Saúde da Família e leitos psiquiátricos. Os profissionais 3 e 4 responderam:

A rede de saúde mental é um serviço ampliado com os meios sociais, cultura, a Estratégia Saúde da Família, trazendo como conjuntos de articuladores do matriciamento com o Hospital Geral de Palmas, o SAMU e até mesmo a família, como parte singular desta rede tão importante para a saúde mental. (Entrevistada 3, 2012)

Falar da rede de atenção à saúde mental é direcionar o usuário para um sonho real de seus meios sociais, culturais, familiares, e da saúde. A rede de saúde mental, aqui no Tocantins, deveria ser mais articulada, muitas vezes não alcança nem um terço da população usuária do CAPS, fazendo com que as ações voltadas aos usuários não abranjam os meios econômicos, sociais, afetivos e civis do usuário. Para mim a rede deve ser repensada. (Entrevistada 4, 2012)

No relato das profissionais 3 e 4, foi feita uma exposição sobre a rede no sentindo mais ampliado, ou seja, a rede na participação dos atores sociais e no acesso à sociabilidade e a respeito da subjetividade, mas no cotidiano a rede está longe de ser efetivada. Pensando no pressuposto de Faleiros (2008), que aborda desenvolvimento do sujeito no poder da autonomia:

[...] implica a procriação, pela consciência, da necessidade que está inscrita na história [...] e pelo descobrimento e uso da própria força no contexto em que as necessidades e as possibilidades se inscrevem. No campo da solidariedade, as possibilidades de afeto e apoio; no campo da cultura, as possibilidades de autoestima e expressão coletiva; no campo das instituições, as possibilidades de garantia de direitos; no campo da economia, as possibilidades de capacitação, emprego e/ou autogestão; no campo da organização, as possibilidades de autorregulação e resistência ao controle, à opressão, à discriminação, à vitimização. $\mathrm{O}$ desenvolvimento 
da autonomia é um processo de negação da tutela e da subalternidade pela mediação da afirmação da própria palavra e da construção das decisões sobre seu próprio destino. (Faleiros, 2008, p. 62)

Seguindo com a entrevistada 2, ela troca o intuito da rede, usando a rede como substituição dos hospitais psiquiátricos, mas termina seu depoimento aproximando-se de um ponto importante da inclusão dos usuários na rede, em um fortalecimento das necessidades de trabalho e a qualidade de vida, já que a maioria das usuárias entrevistadas tem sua renda familiar até um salário mínimo.

Sobre o ponto de vista dos profissionais acerca do CAPS ser o regulador da porta de entrada para a rede de atenção à saúde mental, as profissionais 1,3 , 4 e 5 responderam que o CAPS é a porta de entrada perante as leis estabelecidas pelo Ministério da Saúde; mas os USF, Policlínicas, CAS, CAPSad entre outros polos, também devem ter partes para os cumprimentos das leis. E a profissional 2 declarou que somente a rede é a porta de entrada. A resposta da profissional 2 foi sucinta e sem explicação; não conseguiu atingir o âmbito principal da resposta, deixando claro que não tinha entendido o CAPS como porta de entrada da rede.

Esse não conhecimento da porta de entrada para a rede de atenção à saúde mental revela que as dificuldades estão no entrelaçamento da rede com os profissionais, deixando claro, mais uma vez, que os profissionais devem ter urgentemente uma capacitação para o entendimento da porta de entrada dos serviços substitutivos; a busca da qualidade profissional pode ser a solução para o problema do funcionamento da rede de serviços da saúde mental. Entretanto, não queremos, em nosso estudo, "culpabilizar" ou "vitimizar" os profissionais; somente identificar, no que for possível, o avanço na melhoria da articulação da rede, pois no cotidiano miúdo do exercício profissional da equipe,

Sabemos que diariamente o trabalho profissional esbarra nos limites das políticas públicas e na falta de estratégias de articulação do trabalho em rede, além de outros empecilhos como falta de estrutura física e de acesso dos serviços. Os mesmos, entretanto, não se tornam justificativas para a não realização do exercício profissional. O profissional [...] é capaz de articular e buscar estratégias para a superação destas questões. A criatividade torna-se um dispositivo favorável para 
a superação das barreiras. Novamente ressalta-se que o processo de ação profissional deve ser reinventado a cada demanda. (Bredow e Dravanz, 2010, p. 238)

Em suma, podemos verificar que o desconhecimento e a precariedade do trabalho em rede vêm aprofundando ainda mais o fosso histórico da segmentação das políticas sociais.

\subsection{A perspectiva intersetorial: visão dos profissionais e usuários no acesso à rede}

Este item do estudo está calcado na necessidade de identificar como as equipes interprofissionais dos CAPS articulam as diferentes políticas sociais e a acessibilidade do usuário no sentido de garantir a integralidade da atenção em saúde mental. Entendemos que as intervenções intersetoriais se caracterizam por serem uma articulação integrada entre os serviços de saúde mental, saúde, outras políticas públicas e programas que têm como base as diferentes necessidades de saúde e cidadania dos usuários do serviço no sentido da integralidade.

A noção de coletivo aqui é operada como um espaço múltiplo, que para ser potente precisa se abrir à inclusão das diferenças, dos diferentes e das tensões. Não é possível ativar processos de mudanças querendo se fazer do coletivo um - uma unidade, uma homogeneidade. Coletivo deve sustentar o múltiplo, aquilo que escapa que resiste. Não há mudanças sem resistência e onde há resistência há muito trabalho. (Pinheiro, Guljor, Junior e Mattos, 2007, p. 199)

Sobre o atendimento dos usuários do CAPS nas redes de saúde básica, a profissional 3 relatou: "O atendimento nos USF falha, pois não existe acompanhamento frequente para esse público, porque existe muito preconceito e medo". Os profissionais 1, 2, 4 e 5, responderam que os profissionais desses polos precisam conhecer as propostas da política de saúde mental e ainda falta integração dos polos da rede pública com o CAPS II.

Confirmando a dificuldade do acesso na rede as usuárias entrevistadas, quando indagadas de como são atendidas nos polos da rede pública (Unidade de Saúde, Policlínicas, Saúde da Família, Hospital Geral, entre outras instituições 
dentro do SUS), relatam atendimento ruim. Três (3) usuárias responderam que o atendimento é péssimo e não queriam justificar suas respostas. Duas (2) usuárias falaram que acham o atendimento bom e não têm nada para reclamar. A usuária 7 falou:

$\mathrm{O}$ atendimento fora do ambiente do CAPS é meio estranho, eles pensam que a gente vai pegar as coisas do consultório, [a] mim trata como se eu, além de louca, fosse surda ou não conseguisse entender o que eles falam. Mas além de tudo eles nem [a] mim conhece direito, como o povo daqui do CAPS mim conhece. (Usuária entrevistada 7, 2012)

A usuária 8 disse:

Eu já fui atendida no hospital geral daqui de Palmas e não gostei, tive a sensação de que eles queriam matar eu e aplicou um remédio na minha veia que parecia droga, eu só acordei no outro dia, sem saber onde estava, foi péssimo. Mas quando eu chego ao postinho de saúde perto da minha casa o atendimento são diferentes, eles mim tratam melhor. (Usuária entrevistada 8, 2012)

Vejamos fato relatado:

Acho o atendimento em qualquer lugar público ou privado é totalmente preconceituoso e que deveria todos ir pelo menos conhecer o CAPS, para poder aprender a atender direito as pessoas que têm qualquer transtorno mental. (Usuária entrevistada 1, 2012)

Conforme os relatos, podemos observar que um sujeito acometido de transtorno mental fica suscetível às discriminações na vida social, familiar e no acesso a outras políticas públicas (OMS, 2002, p. 57). Além das dificuldades apontadas pelas usuárias entrevistadas no decorrer do estágio dentro do CAPS II de Palmas, observamos que muitos dos usuários, quando eram submetidos à alta, passavam pouco tempo com o tratamento ambulatorial e logo voltavam para o CAPS. Diante da realidade, a rede tem uma grande contribuição.

O preconceito e o medo da sociedade para com os indivíduos com transtorno mental é algo que devemos discutir nos meios midiáticos para assim 
desmistificarmos o estigma da loucura que impede o exercício da cidadania. O apoio da sociedade é fundamental para a rede de atenção à saúde mental. Esse desafio está na possibilidade de ampliar a cidadania historicamente negada ao portador de transtorno mental, por meio da criação de estratégias de enfrentamento ao preconceito e medo e fortalecendo a rede de atenção à saúde mental:

\begin{abstract}
Além do sofrimento óbvio devido aos transtornos mentais, existe um ônus oculto de estigma e discriminação enfrentado pelos portadores de transtornos mentais. Tanto em países de baixa como de alta renda, a estigmatização de pessoas com transtornos mentais tem persistido ao longo da história, manifestada por estereotipia, medo, assédio, raiva e rejeição ou evitação. Violações de direitos humanos e liberdades básicas e negação de direitos civis, políticos, econômicos, sociais e culturais aos que sofrem de transtornos mentais são uma ocorrência comum em todo o mundo, tanto dentro de instituições como na comunidade. $\mathrm{O}$ abuso físico, sexual e psicológico é uma experiência cotidiana para muitos com transtornos mentais. Além disso, eles enfrentam uma recusa injusta de oportunidades de emprego e discriminação no acesso aos serviços, seguro-saúde e políticas habitacionais. Grande parte disso continua sem registro e, com isso, esse ônus permanece sem quantificação. (Organização Mundial de Saúde, 2002, p. 7)
\end{abstract}

Portanto, a condição de ser mulher, pobre, de baixa escolaridade e negra ocasiona na vida das usuárias uma grande desvantagem, deve ser levado em consideração que as usuárias apresentam condições de extrema vulnerabilidade pessoal e social, que pouco permite o acesso às políticas adequadas à sua convivência social conforme o modelo capitalista. Para Faleiros (2008), o sujeito/ usuário está na fragilidade construída pela sua história e trajetória da realidade da pessoa, que se submetem a procurar redes que envolvem todos os seus problemas sociais, sendo que:

A perspectiva relacional a estruturação, das redes, dos processos é que dá margem à visualização dos ciclos, dos patrimônios, das trajetórias de fragilização e de fortalecimento dos vínculos que permitam mudar ciclos, trajetórias, patrimônios, na dinâmica do trabalho com recursos, redes, no trabalho das mediações globais, particulares e singulares, o que se transforma em estratégia de ação profissional, combinada às estratégias de vida dos indivíduos e grupos. (Faleiros, 2008, p. 65) 
Cabe ressaltar que a história de exclusão da loucura também gera impactos contemporâneos na dificuldade de articulação da rede, pois

[...] a rede de saúde se mostra como um conjunto de pontos fragilmente articulados e burocratizados. No caso da saúde mental, essa situação se agrava, pois, historicamente, sempre houve a fragmentação dos serviços de saúde mental da rede de saúde em geral, consolidando o modelo hospitalocêntrico. Isso gerou uma exclusão do portador de transtorno mental da rede de saúde geral bem como do meio social. (Severo e Dimenstein, 2011, p. 643)

Sobre percepção dos profissionais da dificuldade dos usuários manterem-se fora do CAPS, o profissional entrevistado 3 relata:

O trabalho desenvolvido no ambulatório é parte de tudo isso que acontece aqui no CAPS, mas os usuários não conseguem ser apenas medicados, eles precisam de atenção diária e cuidado constante. Eles voltam porque não tomaram o remédio direito e entraram em surto.

\section{O profissional 1 conclui:}

Tem tudo a ver. A rede tem uma grande falha, porque tem muita burocracia na entrega de sua medicação e, muitas vezes, o usuário também não toma os remédios corretamente. Eles voltam porque pioram, por não terem tomado os remédios corretamente.

Por outro lado, a profissional 5 diz que isso tem a ver com a falta de cuidado dos familiares com a medicação do usuário.

O usuário volta para o CAPS II de Palmas, porque seus familiares não [o] ajudam a tomar o medicamento corretamente, deixam por conta do paciente, e o paciente não tem a possibilidade, ainda, de se cuidar sozinho e a família tem um papel grande sobre este usuário. E acho também que a família faz parte da rede, por isso tem [de] haver com a rede esta entrada e saída do usuário no CAPS e no ambulatório. (Profissional entrevistado 5, 2012) 
Já a profissional 4 diz que "A rede está desestruturada, havendo uma necessidade urgente de fortalecimento, trabalho integrado e um matriciamento da rede."

Frente aos dados verificamos que os profissionais declaram que a rede está desarticulada; entretanto, não apresentam uma clareza sobre o fato da longa permanência dos usuários no CAPS e a falta do trabalho de rede. O trabalho de rede implica em reconhecer ainda as disputas, pois,

A rede é uma articulação de atores em torno, vamos nos expressar assim, de uma questão disputada, de uma questão ao mesmo tempo política, social, profundamente complexa e processualmente dialética. Trabalhar em rede é muito mais difícil do que empreender a mudança de comportamento... (Faleiros, 2008, p. 25)

Acreditamos que o envolvimento do CAPS com o ambulatório deve ser constante para que se possa ter uma estratégia de cuidado e efetiva inclusão social do sujeito/usuário. $\mathrm{O}$ ambulatório tem sua contribuição na autonomia do usuário, desenvolvendo atividades e compartilhando o seu trabalho com vários setores.

[...] o ambulatório, no âmbito da reforma psiquiátrica, deve seguir as diretrizes do SUS, podendo englobar unidades básicas/centros de saúde e ambulatórios especializados inseridos ou não em policlínicas. As atividades desenvolvidas devem concentrar-se nos atendimentos individuais, no atendimento grupal, nas visitas domiciliares e nas atividades comunitárias, especialmente na área de referência, sendo função do gestor local definir seu papel na rede de saúde. (Severo e Dimenstein, 2011, p. 642)

Outro aspecto importante é que os profissionais têm que se articular com a rede; essa necessidade deve ser matriciada. No entanto, não podemos esquecer que a precarização das políticas sociais dificulta o envolvimento e melhor desempenho da equipe. Outro aspecto, também, é a falta de preparo da equipe para trabalho de matriciamento.

Os técnicos, em algumas rodas de conversa, apontam como dificuldade o despreparo das equipes da atenção básica em lidar com essa demanda. Essa realidade é encontrada nacionalmente, havendo uma forte resistência das equipes dos CAPS em dar a retaguarda para a atenção básica, pois essa estratégia é vista como mais 
uma tarefa a ser inserida na rotina desses serviços (Dimenstein e Liberato, 2009). Enquanto isso, os técnicos da atenção básica não se sentem capacitados para atender à demanda de saúde mental na atenção primária, ficando desassistida grande parte da população. Os usuários que entram nos serviços substitutivos na cidade acabam sendo atendidos, no campo da saúde mental, apenas em serviços especializados ou nos hospitais psiquiátricos. A dificuldade de articulação entre os serviços substitutivos e as intervenções fragmentadas e pouco flexíveis auxiliam na manutenção da circulação dos usuários no circuito psiquiátrico, onde as estruturas de atendimento comunitário vêm complementar a internação psiquiátrica (Severo e Dimenstein, 2011, p. 651)

Acreditamos que é necessário a capacitação profissional no desempenho da rede de atenção à saúde mental e a articulação da rede com outras políticas públicas. Sabemos que capacitação é um pequeno passo, que não supera os problemas estruturais atuais das políticas sociais, mas contribui para criação de novos caminhos no trabalho da equipe.

\subsection{CAPS e a cidadania fortalecendo a rede:}

Neste item analisaremos como vem sendo trabalhada a questão da cidadania dos usuários e qual é percepção destes. Ao questionar usuárias entrevistadas sobre seus conhecimentos das leis que garantem os direitos das pessoas com transtorno mental, cinco (5) usuárias relataram que não têm conhecimento sobre nenhuma lei que garanta os seus direitos como indivíduo com transtorno mental. A usuária 1 respondeu:

Eu não conheço nenhuma lei que garanta meus direitos, deveria ter uma oficina e algumas palestras sobre os nossos direitos e as leis que a gente tem aqui no CAPS, eu iria achar era bom, mas eles não falam sobre estes direitos. (Usuária entrevistada 1, 2012)

A usuária 2 respondeu:

Eu não sei o que é direito no nosso país, porque tudo que eu faço é errado, as leis de diretos para mim, como doida, são poucas, mas eu acredito que são boas, eu 
nunca vi e nem pude ler sobre essas leis, ninguém nunca mim falou disso. (Usuária entrevistada 2, 2012)

Esse fato relatado pelas usuárias demonstra que temos uma necessidade "urgente" de trabalhar os direitos sociais dos portadores de transtornos mentais. De acordo com Vasconcelos (1997), os usuários atendidos pelos Assistentes Sociais devem saber que seus direitos não são objetos de favor ou doação e sim próprios de cidadãos que têm seus direitos como sujeitos sociais e assim criticar, conscientizar e buscar na luta dos movimentos os direitos reais. Devem ser demonstrados que os direitos são reais na rede de saúde mental e devem ser reconhecidos pelos usuários que têm transtorno mental.

Sobre participação dos usuários nos movimentos sociais, as usuárias pesquisadas falaram que não participavam de nenhum movimento social e apenas duas (2) justificaram suas respostas. Disseram:

Eu não participo dos movimentos sociais porque muitos que tentei entrar, as pessoas me chamaram de doida e tem preconceito e isso mim deixou muito triste e para eu não piorar da minha doença mental, eu saí e até xinguei eles todos. O Movimento social era sobre os moradores do meu bairro. (Usuária entrevistada 1, 2012)

Usuária 8 relatou:

Eu nunca fui chamada para participar de nada, os movimentos sociais que eu gostaria de participar são aqueles que falam sobre a minha doença e sobre a saúde, mas nunca chamaram, até passeata de político eu gostaria de participar, mas nunca me chamaram, sou inútil. (Usuária entrevistada 8, 2012)

A usuária se aproximou do movimento da luta antimanicomial, mas não conseguiu explicá-lo; este movimento demonstra à população de que eles são sujeitos sociais e cidadãos conscientes e críticos. Cidadãos que buscam muito além de favores, buscam o reconhecimento e os valores. Diante do papel que se pode tomar para entender o trabalho da rede junto à saúde mental, 
[...] o trabalho em saúde mental se concretiza quando a equipe acolhe e interage, em sua prática, com a realidade vivenciada pelo usuário. O deslocamento da equipe de um serviço organizado e formalizado para o local de produção de saberes e práticas comunitárias promove a territorialização, importante no processo de inclusão social. (Schneider, 2009, p. 81)

Vasconcelos (2010) salienta a importância histórica da ação contínua de dois movimentos sociais mais importantes: $\mathrm{O}$ movimento antimanicomial visa à desconstrução do estigma da loucura na sociedade envolvendo os trabalhadores do campo, os usuários e familiares, buscando sua autonomia por dentro da luta na sociedade civil. E o movimento de reforma psiquiátrica, com articulações mais institucionais, no campo universitário, dos trabalhadores e, em especial, na gestão estatal, com o interesse popular-democrático. Os dois movimentos coexistem e estão ligados e articulados;

no nosso campo da saúde mental, se salienta a importância histórica e da contínua ação política de nossos dois movimentos sociais mais importantes: o movimento antimanicomial, com base maior na sociedade civil, em trabalhadores e principalmente usuários e familiares, e o movimento de reforma psiquiátrica, mais amplo, e com articulações mais institucionais, no campo universitário, dos trabalhadores e principalmente na gestão estatal. Quando diminui o espaço político neste campo institucional e no Estado, o movimento antimanicomial ganha ainda mais importância, porque tem mais autonomia para mobilizar forças na sociedade para pressionar de fora o Estado. [...]. Entretanto, a atual conjuntura ainda nos requer avaliar melhor outras de suas facetas e paradoxos, particularmente no tocante à sua avaliação e à estratégia teórico-política que sustenta a ação no processo de levar a reforma psiquiátrica avante em um contexto mais global como este. (Vasconcelos, 2010, p. 23-24)

Os profissionais, quando questionados sobre a proposta social e educativa da saúde mental ao usuário do CAPS, em sua maioria relataram que não havia nenhum destes aspectos no trabalho. Em nosso ponto de vista, a falta de visibilidade desses aspectos no trabalho da equipe enfraquece os ideais de consolidação da Reforma Psiquiátrica. 
A partir do momento em que os grupos adquirem essa liberdade de viver seus processos, eles passam a ter uma capacidade de ler sua própria situação e aquilo que se passa em torno deles. Essa capacidade é que vai lhes dar um mínimo de possibilidade de criação e permitir preservar exatamente esse caráter de autonomia tão importante. (Guattari, 1986, p. 46)

\section{Considerações finais}

O estudo apresentado buscou uma aproximação das dificuldades na inserção dos usuários nas políticas públicas e na sua participação social. É fundamental avançarmos em pesquisas que contribuam na materialidade para o projeto político do Serviço Social que, entre seus princípios, contrapõe-se a quaisquer formas de discriminação e compromete-se com a luta pela superação da violação de direitos. Com base nos resultados, pelos profissionais e dos usuários, constatou-se que a rede precisa da participação dos gestores, familiares, de capacitações para os profissionais do CAPS e participação e articulação dos Agentes de Saúde, Saúde da Família e Ambulatório Psiquiátrico. Compreende-se que os profissionais sabem pouco da rede de Atenção à Saúde Mental e precisam saber mais. Ainda há uma grande necessidade de estruturar a rede de atenção à saúde mental, além de uma necessidade urgente de fortalecimento e vínculo com a sociedade em geral.

"Este é um pensar que percebe a realidade como processo, que a capta em constante devenir e não como algo estático. Não dicotomiza a si mesmo na ação. Banha-se permanentemente na temporalidade cujos riscos não teme."’3

Recebido em 23/9/2013 - Aprovado em 17/3/2014

3. Freire, P. Pedagogia do oprimido. São Paulo: Paz e Terra, 1987. 


\section{Referências bibliográficas}

AMARANTE, Paulo Duarte de Carvalho. Asilos, alienados e alienistas. In: AMARANTE, Paulo (Org.). Psiquiatria social e reforma psiquiátrica. Rio de Janeiro: Fiocruz, 1994.

et al. Loucos pela vida: trajetória da reforma psiquiátrica no Brasil. Rio de Janeiro: Fiocruz, 2002.

. Cidadania e Reforma Psiquiátrica. In: MELLO E SOUZA, M. C.; COSTA, M. C. S. (Orgs.). Saúde mental numa sociedade em mudança. Ribeirão Preto: Legis Summa/FIERP, 2005.

. Saúde Mental e Atenção Psicossocial. Rio de Janeiro: Fiocruz, 2007.

BRASIL. Ministério da Saúde. Secretaria de Atenção à Saúde. Coordenação Geral de Saúde Mental e Coordenação Geral de Atenção Básica. Saúde Mental e Atenção Básica: $\mathrm{O}$ vínculo e o diálogo necessários. Brasília, 2003.

. Ministério da Saúde. Reforma Psiquiátrica e Política de Saúde Mental no Brasil. Brasília, 2005.

Portaria n. 336/2002, de 19 de fev. 2002. Brasília: Ministério da Saúde. Disponível em: <http://drt2001.saude.gov.br/as/PORTARIA/port2002/PT336.htn>. Acesso em: jan. 2011.

. Portaria/GM n. 3.088, de 23 de dezembro de 2011. Brasília, 2011.

. Constituição Federal de 1988. 26. ed. Seção II — Da Saúde (arts. 196-200). Brasília, 2012. p. 55.

BREDOW, Suleima Gomes; DRAVANZ, Glória Maria. Atuação do Serviço Social na Saúde Mental: entre os desafios e perspectivas para efetivação de uma política intersetorial, integral e resolutiva. Textos \& Contextos, Porto Alegre, v. 9, n. 2, p. 229-243, ago./dez. 2010.

CENCI, Adriane; COSTAS, Fabiane Adela Tonetto. Subjetividade social e subjetividade individual nas dificuldades de aprendizagem. In: SEMINÁRIO INTERNACIONAL DE REPRESENTAÇÕES SOCIAIS, SUBJETIVIDADE E EDUCAÇÃO, 10., Curitiba, 7 a 10 de novembro de 2011 .

CFESS. Parâmetros para a atuação de assistentes sociais na saúde. Brasília, 2009. 
CHACON, Miguel C. M. Deficiência mental e integração social: o papel mediador da mãe. Rev. Bras. Educ. Espec. [on-line], v. 3, n. 5, 1999.

COSTA, Jurandir Freire. História da psiquiatria no Brasil. Rio de Janeiro: Campus, 1989.

CUNHA, Maria Clementina Pereira. Cidadelas da ordem: a doença mental na República, São Paulo: Brasiliense, 1990.

FALEIROS, Vicente de Paula. Estratégias em Serviço Social. 8. ed. São Paulo: Cortez, 2008.

FRAYZE, Pereira J. A. Psicanálise, teoria dos campos e filosofia: a questão do método. In: L. BARONE (Org.). O psicanalista: hoje e amanhã. O II encontro psicanalítico da teoria dos campos por escrito. 1. ed. São Paulo: Casa do Psicólogo, 2002.

GUATTARI, Félix; ROLNIK, Suely. Micropolítica: cartografias do desejo. 2. ed. Rio de Janeiro: Vozes, 1986.

IAMAMOTO, Marilda Vilela. O Serviço Social na contemporaneidade: trabalho e formação profissional. 10. ed. São Paulo: Cortez, 2004.

. As dimensões ético-políticas e teórico-metodológicas no Serviço Social contemporâneo. In: . Serviço Social e saúde formação e trabalho profissional. 3. ed. São Paulo/Brasília: Cortez, 2008. p. 161-196.

LEME, Carla Cristina Cavalcanti Paes. O assistente social na saúde mental, um trabalho diferenciado, uma prática indispensável. In: . A prática do assistente social na saúde mental. Rio de Janeiro: Ed. da UFRJ, 2013.

MACHADO, Graziela S. O trabalho do Serviço Social nos CAPS. Textos \& Contextos, Porto Alegre, v. 8 n. 2, p. 241-254, jul./dez. 2009.

MATTOS, Ruben Araújo de. Os sentidos da integralidade: algumas reflexões acerca de valores que merecem ser defendidos. In: PINHEIRO, R.; MATTOS, R. A. (Orgs.). Os sentidos da integralidade na atenção e no cuidado à saúde. Rio de Janeiro: Instituto de Medicina Social, Universidade do Estado do Rio de Janeiro/Abrasco, 2001. p. 39-64.

MENICUCCI, Telma Maria Gonçalves. Política de Saúde no Brasil: entraves para universalização e igualdade da assistência no contexto de um sistema dual. Serviço Social \& Sociedade, São Paulo, ano XXVI, n. 87, 2006.

NETTO, José Paulo. A construção do Projeto Ético-Político do Serviço Social. In: . Serviço Social e saúde formação e trabalho profissional. 3. ed. São Paulo: Cortez, 2008. p. 141-160. 
NUNES, Carina; MACHADO, Graziela; BELLINI, Maria Isabel. A qualificação e a contribuição do processo de trabalho dos Assistentes Sociais no campo da saúde mental. Textos \& Contextos, n. 2, dez. 2003.

ORGANIZAÇÃO MUNDIAL DE SAÚDE. Cuidar sim, excluir não: livro de recursos sobre saúde mental, direitos humanos e legislação. Departamento de Saúde Mental e Abuso de Substâncias, Organização Mundial de Saúde, 2002.

PINHEIRO, Roseni; GULJOR Ana Paula; JÚNIOR, Aluisio Gomes da Silva; MATTOS, Ruben Araujo de. Desinstitucionalização da saúde mental: contribuição para estudos avaliativos. Rio de Janeiro: Cepesc/IMS/Lappis/Abrasco, 2007.

PORTO, Mauricio; SERENO, Deborah. Sobre Acompanhamento Terapêutico. In: . A rua como espaço clínico. São Paulo: Escuta, 1991.

RABELO, Ionara V. M.; TAVARES, Rosana C.; FARIAS, Yuza R. Prefácio. In:

et al. (Orgs.). Olhares: experiências de CAPS. Goiânia: Editora Kelps, 2009.

RABELO, Josinês Barbosa. A intersetorialidade da política de saúde e os reflexos no desenvolvimento das ações de saúde mental. Recife: Prefeitura Municipal do Recife, s/d.

RESENDE, Heitor. Política de saúde mental no Brasil: uma visão histórica. In: TUNDIS, Silvério Almeida; COSTA, Nilson do Rosário (Orgs.). Cidadania e loucura: políticas de saúde mental no Brasil. Petrópolis: Vozes, 1987. p. 15-73.

ROVERSI-MONACO, Fábio. Descentralização e centralização. In: BONNIO, N. et al. Dicionário de política. 5. ed. Brasília: Ed. da UnB, 1993.

SCHNEIDER, Alessandra Ritzel dos Santos. A rede de atenção em saúde mental: a importância da interação entre a atenção primária e os serviços de saúde mental. Ciência \& Saúde, Porto Alegre, v. 2, n. 2, p. 78-84, jul./dez. 2009.

SEVERO, Ana Kalliny; DIMENSTEIN, Magda. Rede e intersetorialidade na atenção psicossocial: contextualizando o papel do ambulatório de saúde mental. Psicologia: Ciência e Profissão, v. 31, n. 3, p. 640-655, 2011.

SILVEIRA, Marília Rezende. A saúde mental na atenção básica: um diálogo necessário. Tese (Doutorado em Enfermagem) — Universidade Federal de Minas Gerais, Belo Horizonte, 2009.

VASCONCELOS, Ana Maria. Serviço Social e prática reflexiva. Revista da Faculdade de Serviço Social da UERJ, Rio de Janeiro, n. 10, jul. 1997. 
VASCONCELOS, Eduardo Morão. Serviço Social e Interdisciplinaridade: o exemplo da saúde mental. Serviço Social \& Sociedade, São Paulo, v. XVIII, n. 54, p. 132-157, 1997.

(Org.) Saúde mental e Serviço Social: o desafio da subjetividade e da interdisciplinaridade. São Paulo: Cortez, 2000.

. Saúde mental e Serviço Social: o desafio da subjetividade e da interdisciplinaridade. 4. ed. São Paulo: Cortez, 2008.

. Desafios políticos no campo da saúde mental na atual conjuntura: uma contribuição ao debate da IV Conferência Nacional. São Paulo: Hucitec, 2010.

YASUI, Sílvio. Ruptura e encontro: desafio da reforma psiquiátrica brasileira. Rio de Janeiro: Editora Fiocruz, 2006. 